\title{
Advances in detection of stress tolerance in plants through metabolomics approaches
}

\author{
Naeem Khan*1, Shahid Ali ${ }^{2}$, Muhammad Adnan Shahid ${ }^{3}$, Ardashir Kharabian-Masouleh ${ }^{4}$ \\ ${ }^{1}$ Department of Plant Sciences, Quaid-I-Azam University Islamabad, Pakistan \\ ${ }^{2}$ Plant Epigenetics and Development, Northeast Forestry University, Harbin, China \\ ${ }^{3}$ Horticultural Sciences Department, IFAS, University of Florida, USA \\ ${ }^{4}$ Queensland Alliance for Agriculture and Food Innovation (QAAFI), The University of Queensland, Australia
}

*Corresponding author email: naeemkhan@bs.qau.edu.pk

\begin{abstract}
Heat and drought stresses are presently the principal risk on world's food quantity, limiting yield. Both of these two stresses affect plants metabolism, physiological and morphological processes, which ultimately reduces the productivity. The plant cell develops different stress induced self-defence mechanisms to reduce the effect of stresses. These defence mechanisms are developed by modifying gene expression pattern, which results in qualitative and quantitative deviations in proteins synthesis, leading to the modulation of certain metabolic and defensive pathways. New metabolic profiling technologies offer a great opportunity for biologist to understand defence mechanism of plants under stress conditions. Metabolomics technologies presently enabled the using of different multi-variate analyses, generated from various hyphenated and chromatographic discovery systems, such as gas or liquid chromatography together with mass spectrometry, or nuclear magnetic resonance (NMR) based methods. Investigation and mining of metabolomics data can be done through a blend of different statistical methods, such as independent component analysis and analysis of variance. Metabolomics in combination with gene expression, protein interaction and other different regulatory pathways can be useful to diverse organisms with trivial alterations. In recent time, this technology has been used to investigate drought tolerance in plant crops to find particular stress related patterns in metabolic expression. These studies identified the vital roles of primary and secondary metabolites associated with abiotic stress tolerance.
\end{abstract}

Keywords: Drought stress, Metabolomics, mRNA.

\section{Introduction}

\section{Plant metabolomics}

A metabolome is a complete set of metabolites accumulated by organism in its lifespan. The metabolites have vital roles in biochemical processes of organisms (Fiehn, 2002; Patti et al., 2012). Metabolomics is one of the most rapidly growing technologies in biological investigation of stress tolerance mechanisms. This technology is widely utilised in plant research and comprises of metabolic fingerprinting, profiling and targeted analysis (Fiehn, 2002; Shulaev, 2006). Genome wide association study based on metabolites has appeared as an advancing genetic approach to divide the biochemical and genetics bases of metabolism in crop plants (Luo, 2015).

The metabolomics study describes the complete metabolite accumulation in the cellular location at a precise stage of growth in the cell (Hollywood et al., 2006). Metabolomics are used as a key instrument to understand the environmental responses in plants (Bundy et al., 2007). Recently, they are being used as key instrument to study biogenic volatile compounds produced by various plant species (Lijima, 2014). Metabolomics are more adaptable to changes as compared to transcriptomes and proteomes. There are many regulatory genes, under environmental stresses, controlling a variety of secondary metabolites in plants, which are the end products of various biochemical pathways. Those metabolites can be considered as primary or secondary, though a firm judgment cannot be made and relationships amongst the two classes are universal. Primary metabolism contains the additional vital metabolites such as those involve in central carbohydrate metabolism (Koch, 2004; Rontein, 2002), while, secondary metabolism may be related to communications with environmental signals, comprising cell signalling and interspecies communication (Mitchell-Olds, 1998; Wink, 1988). The biosynthetic pathways of key metabolites are well preserved amongst species that explain the growth characteristics of various species (Mitchell-Olds, 1998).

The research has contributed to our valuable understanding about the importance and mechanism of metabolites for plant development. This is more implied to primary metabolism rather than metabolism at secondary level, due to the fact of dissimilarity in metabolic content. The maximum information about secondary metabolism is mainly obtained from advancing in genetic methods, where specific phenotypic traits may be linked to alterations in particular metabolites. Classically, such investigation based on targeted approaches where only a single metabolite that could be sensed (Rochfor, 2008; Yonekura-Sakakibara, 2008). Metabolomics studies in rice have so far demonstrated that the various metabolites can improve seed germination (Moongngarm and Saetung, 2010). The uniqueness of metabolites amongst wild type and mutant plants (Wakasa et al., 2006), the metabolome profiling at several phases of improvement (Tarpley et al., 2005), and the analysis of normal metabolite distinction amid altered rice varieties has been reported (Kusano et al., 2011). 


\section{Synergistic effects of metabolites on stress tolerance}

Drought, heat and salinity greatly diminish production in crop plants if present alone or in association. Breeding for developing stress tolerance in crop plants is the most important method to manage with growing environmental tasks in agriculture. Significant investigation has been carried out for dissecting plant responses to environmental stresses (Urano et al., 2009; Obata and Fernie, 2012), but the interactions amongst diverse stresses and what mechanism controls inert-stress tolerance mechanism has been far less studied (Cairns et al., 2013; Suzuki et al., 2013). Due to complexity, especially stereo-chemical orientations of atoms, the structure of metabolites is less understood than genes and proteins (Lewis and Garrod, 2002). Genotypic and environmental interaction also affects the levels and composition of plant metabolites. Metabolomics can play a significant role in the study of stress biology in plants and animals through the identification of various compounds. These may include by-products of stress metabolism and stress signal transduction molecules that are involved in adaptation of plants to stresses. These might be confirmed through direct measurements, changes in proteome and transcriptome expressions and confirmed by mutant analysis (Ideker et al., 2011). When plant sensed a change in environmental condition, the signal transduction pathways initiates and activates different proteins compounds that reinstate homeostasis (Mittler et al., 2004). Whole metabolomics analysis for each and every plant is costly, but through metabolic profiling a subclass of metabolites can be analysed at any time or growth stage of the plant (Arbona et al., 2013).

Plants show different responses when they sense abiotic stimuli, which are related to a particular stress tolerance mechanism. Modification in primary metabolism is considered the most apparent in all metabolic responses and include alterations in the levels of sugars/sugar alcohols, amino acids and tricarboxylic acid cycle intermediates, displaying common tendencies in environmental stress responses. However, variations in the secondary metabolism are very specific to a specific stress and specific to species as well. For example, polyamines and sugars might be responsible for adaptation to extreme cold temperatures in Thellungiella accessions (Colinet et al., 2012).

Some of the metabolic compounds related to abiotic stress tolerance include polyols mannitol, sorbitol, dimethylsulfoniopropionate, sucrose, trehalose, fructan, proline and ectoine that assist as osmolytes and osmo-protectant to guard plants under various stresses. A range of epi-cuticular waxes defend plants from extra water loss through drought stress and provide protection against the antagonistic activities of various pathogens. Many minor molecules like, ascorbic acid, carotenoids, tocopherols and anthocyanins etc. guard plants from oxidative damage related to a diversity of stresses and protect them by hunting active oxygen intermediates, produced during different stress conditions. The production of phytoalexins and initiation of phenyl-propanoid pathway and lignin biosynthesis are associated with plant stress defence mechanism. Plant biosynthetic molecules like salicylic acid, methyl salicylate, jasmonic acid and methyl jasmonate are formed under stress. They also act as signalling molecules triggering systemic defence in crop plants (Shulaev, 2006).

In recent years, metabolomics have been practiced for numerous purposes like: (1) assessment of the effect of stress in plants, (2) pursuing the contribution of a specific compound within a specific biosynthetic or secondary deprivation pathway, and (3) organisation of various plant samples (Saito, 2010). A targeted or a non-targeted method can be applied, depending on the specific objective. The technique used for analysis might affect the assembly of compounds in a metabolomics platform. Most of the presently used metabolomics platform is based on a targeted approach. As a whole, the real metabolic organization of a given plant species is the outcome of a specific gene expression profile. Precursors and intermediate molecules are activated to produce bioactive molecules, when a certain metabolic pathway is activated. Plant hormones are basically involved in controlling the production of these precursors and intermediate compounds that can trigger or deactivate diverse metabolic steps (Zhao and Verpoorte, 2005).

The stability, defence and signalling of metabolites can be used to measure plant tolerance to different abiotic stress conditions (Kim et al., 2007; Kerchev et al., 2012). It has been found that sugars or sugar alcohols and amino acids are the utmost vital primary metabolites that accumulate in plant parts, when exposed to stresses (Krasensky et al., 2012; Valerio, 2011). However, due to the alterations in concentration, fluctuation in secondary metabolite levels is characteristically, due to intricate regulatory process (Arbona et al., 2013).

\section{Metabolomics profiling in crop plants}

Metabolite based profiling study in maize showed that primary damages of salt stress are associated with the osmotic component. In calculation, outcomes were reliable when, osmotic effects were stronger in leaves than in roots (Lee et al., 2012). Though, these findings have the restriction of not showing the underlying link between precise metabolic variations and stress tolerance. Furthermore, they do not permit the documentation of the basic molecular mechanisms (Sanchez et al., 2011). Metabolite fingerprints to cold stress were obtained for Drosophila melanogaster individuals (Korn et al., 2010) and showed that the strategies to cold adaptation might be the same within all members of the kingdom. Janská et al. (2011) confirmed all the significant metabolic variations, stirring in cold acclimatization, reenforcing the impression that the combination of cryoprotectant molecules is of great valve (Guy et al., 2008). Amongst these cryo-protectans, sugars, sugar alcohols and proline were exposed to be of higher significance. Therefore, the accretion of these molecules in modified individuals could contribute to a higher cold stress tolerance (Witt et al., 2012). In the same way, accumulation of sugar molecules (maltose, sucrose, sugar alcohols, and trehalose) helps in plant acclimation to high temperature stress. Non-targeted metabolomics approaches have shown consequences on CoA pathways that might not be otherwise found (Widodo Patterson et al., 2009).

Charlton et al. (2008) revealed augmented levels of leucine, isoleucine, proline, valine, homoserine and threonine as well as myo-inositol, malate and GABA in pea leaves in simulated field conditions using NMR analysis. However, they noted no significant increase in leucine and isoleucine. Alvarez et al. (2008), noted enhanced ranks of proline, malate, pcoumarate, and caffeate by means of an LC-MS method for maize xylem sap; though, ferulate reduced under adverse environmental conditions. Sanchez et al. (2011) examined metabolic responses in Lotus japonicus species and recognised associations among the level of stress and the extent of alterations in the metabolite profiles. Maximum 


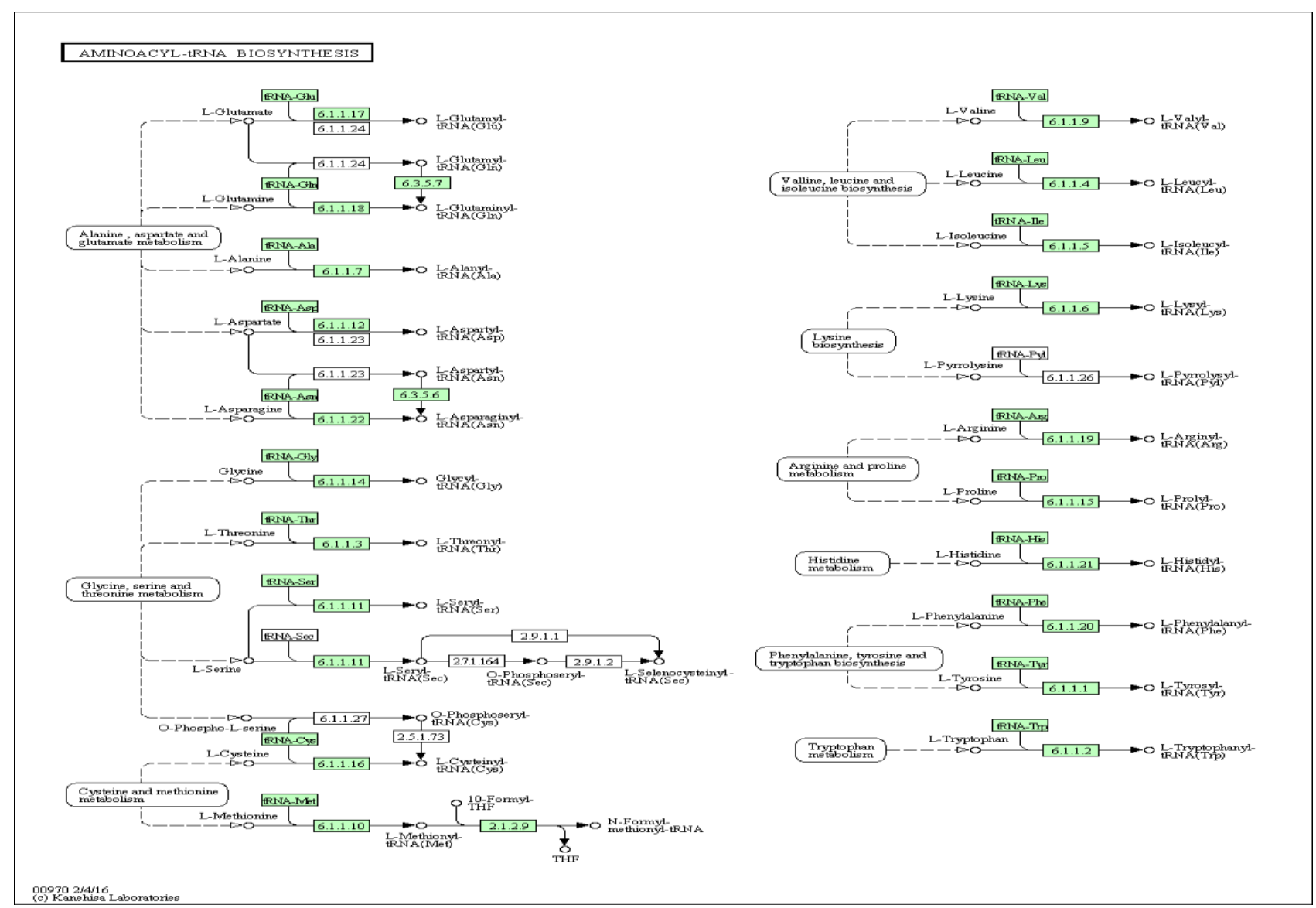

Fig 1. Aminoacyl-tRNA pathway analysis in Arabidopsis thaliana (thale cress).

\section{GLYCINE, SERINE AND THREONINE METABOLISM}

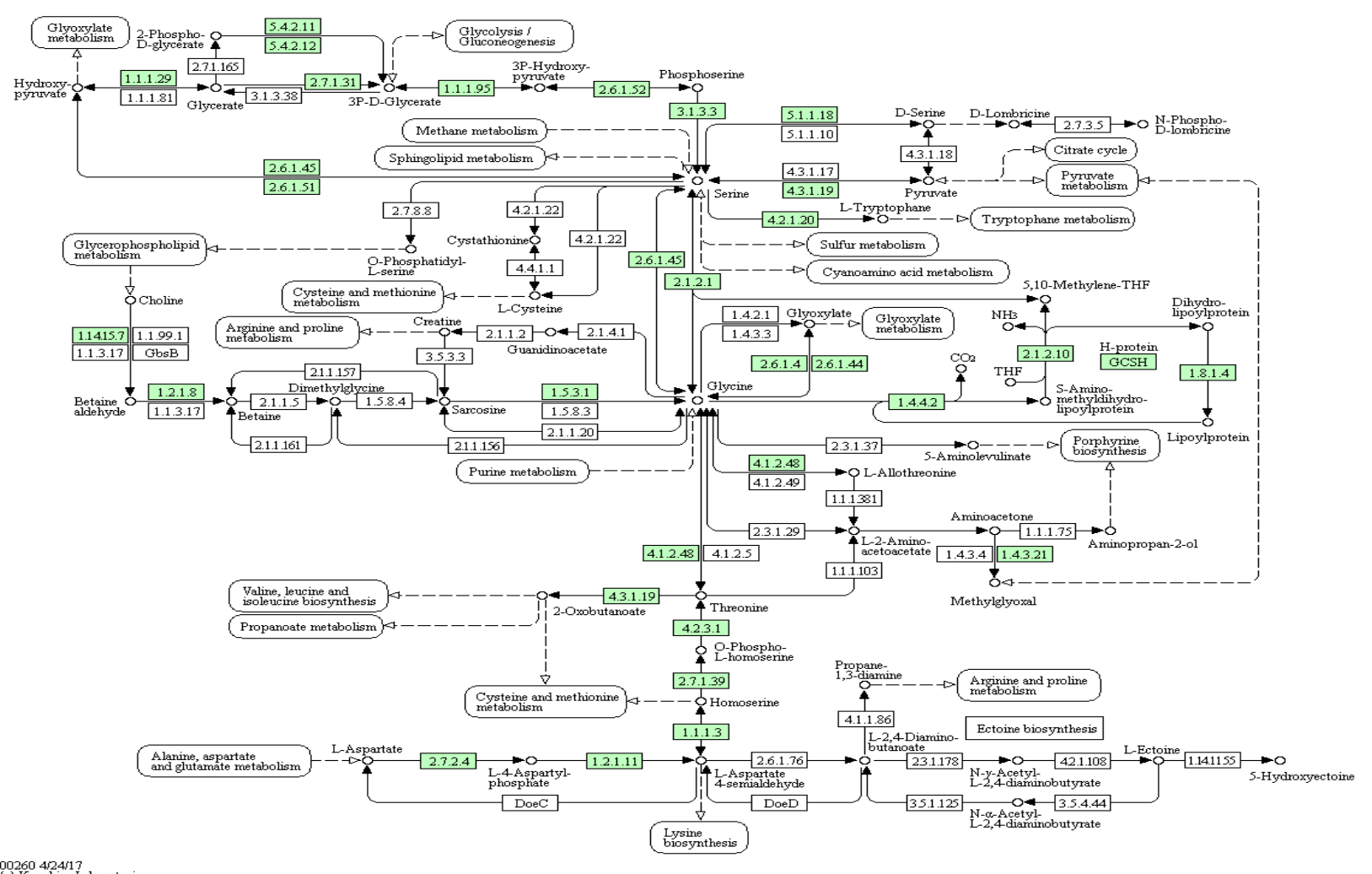

Fig 2. Glycine, serine and threonine metabolism in plants during environmental stresses. 
variations were pragmatic in sugars and polyols. They also defined a study investigating the alterations in the metabolite profiles of Lotus species, which shown that metabolite variations are preserved within species but water-deficit may also affect many species-specific pathways (Sanchez et al., 2011). Together in both studies, about $90 \%$ of all identified significant variations were increased. Witt et al. (2012) found a reduction in quinic acid and pyruvic acid and increase level of histidine, putrescine, proline and phenylalanine in the leaves of maize crop in response to drought treatment.

\section{Environmental stresses encountered by plants}

Stress is any modification in growth state that disturbs metabolomics homeostasis and needs regulation of metabolic pathways in a course that is usually mentioned as acclimation. Heat and drought stress are presently the principal risk on world's food supply, limiting crop yield (Oritz, 2008). The degree and harshness of stress affected agricultural property is expected to deteriorate as a result of scarce irrigation resources, deteriorating water tables and global warming. Abiotic stress is therefore, the key risk towards the living world most exactly for the plant kingdom (Tardieu and Tuberosa, 2010). Plants have adopted numerous biochemical, physiological and metabolic strategies in order to combat such abiotic stresses. More frequently, it is difficult to guess the complex signalling pathway that are activated or deactivated in reply to different abiotic stresses (Chawla et al., 2011). Most of the plant system biology methods depend on four main axes are genomics, proteomics, transcriptomics and metabolomics, which provide us with detailed information about the topology and dynamic function of a molecular system (Yuan et al., 2008; Chawla et al., 2011).

\section{Drought stress tolerance and plant metabolism}

A chief restraint to yield and quality in numerous crop species is the accessibility of water during growth season (Perry et al., 2005; Morison et al., 2008). Drought tolerance is vital to alleviate and surge food production since domestication has restricted the genetic range of crops such as wild wheat, leading to cultivated species, modified to artificial environments and lost lenience to stress episodes (Kaur et al., 2002). World's temperature is growing at a rate of $0.18^{\circ} \mathrm{C}$ every decade (Hansen et al., 1988). Future climate changes will also be affected by greater variability in temperature and augmented frequency of hot days (Pittock, 2003). Drought, being also a very significant environmental stress, strictly harms plant development and expansion, restrictions of plant production and performance of crop plants (Shao et al., 2009). One of the most vital physiological parameters being affected by drought is photosynthesis. In this sense, both water and salt stresses are pretty alike producing a liberal and severe drop in the $\mathrm{CO}_{2}$ assimilation capacity. As significance of severe climatic changes crosswise the globe, risk of the existence of more recurrent drought spells is expected. Still, in view of several climatic variations, scientists recommended that in several areas of world, crop losses due to growing water scarcity will additionally worsen. In order to adapt new crop varieties, we need to understand plant responses to various stimuli (Halford and Hey, 2009).

Plants familiarise and adapt to those changes that occur over a large time scale at their ecological places. These adaptations occur through evolutionary process that acts at the genetic level in populations and among species over several groups. Plant drought adaptive strategies include escape, avoidance and tolerance (Nilson and Orcutt, 1996). Among them, escape signifies a process developing a high degree of elasticity in the plant life cycle that enables them to 'sidestep' periods of water scarcity, for example, quick flowering and seed-set in spring earlier summer drought. Avoidance characters promote to exploit water uptake and reduce water loss, for example, through augmented root density and decreased leaf water conductance. Lastly, tolerance denotes to the ability of plants to reserve cellular metabolic activity when tissue water potential drops, frequently over osmotic adjustment and differences in the pliability of cell walls (Collins et al., 2008; Richardson, 1993).

ABA is one of the utmost significant metabolites formed in reaction to water stress in crop plants (Bartels and Sunkar, 2005). In recent decade, a key ABA biosynthesis gene has been recognised as $\mathrm{ABA}$ 80-hydroxylases that regulates $\mathrm{ABA}$ levels during seed imbibition and stress conditions (Saito et al., 2004; Kushiro et al., 2004). It is probable that regulation of ABA levels may help plant to survive under situations of drought stresses. Certainly, an insertional mutant of CYP707A3, which was articulated most abundantly among 4-CYP707A members in stress conditions, showed high drought tolerance with a connected decrease in the rate of transpiration. Development in the omics technology has permitted a general method to acquire tolerance to drought, built on the amount of the expression of large number of genes and their products. Profiling of mRNA has been used to examine the fluctuations in gene expression in answer to water deficit (Ozturk et al., 2000). Soluble sugars, that are produce during harsh environmental conditions, can act as motioning molecules in stress (Chaves et al., 2009) and work in association with phytohormones as part of the sugar detecting and indicating complex system in plants (Rolland et al., 2006). The starch content declines in response to drought stress, while soluble sugars tend to rise (Chaves, 1991). However, under severe dehydration stress soluble sugar may also tend to decrease (Pinheiro et al., 2001). This change in sugar content also bring changes in the expression of genes and proteomic patterns, particularly in photosynthetic metabolism (Geigenberger and Stitt, 2004).

It is fact that no large scale, drought specific study has been carried out regarding metabolomics. However, several studies have explored the role of sugar and enzymes during drought stress (Boyer and Westgate, 2004). Water deficit condition is a major treat to produce grain, especially in maize crop, where a lack in assimilate source has been specified as the causal agent of infertility and reduced grain filling. Recently, the invertase activity has been studied and suggested a restrictive factor for grain filling in maize under stress condition. In maize, the QTL designed for invertase activity show mapping near Ivr2, an invertase-encoding gene. Additionally, co-location between the sucrose-P synthase and ADP-glucose pyrophosphorylase has been reported in young maize plants exposed to drought (Pelleschi et al., 2006). These studies have disclosed that how metabolites and proteins can play key roles in stress tolerance and in the formation of stress tolerant crops. Furthermore, these studies provide new basis for the discovery of unique methods that would help in drought tolerance of plants (Oksan and Saito, 2005).

The ability to survive against partial water availability needs a complex blend of different genetic-, physiological-, and genome-based defence plans to keep functional veracity of cells and the entire organism. Disruption of water stability induces metabolic changes and accumulation of metabolites such as proline, ascorbic acid, glutathione and detoxifying 
enzymes. Yet, a more detailed metabolic profile in droughtstressed plants with above and below-ground organs is not available (Davies, 2006).

\section{Salt stress tolerance and plant metabolism}

The second largest abiotic stresses that disturb germination, crop growth and productivity is soil salinity. When soil $\mathrm{pH}$ exceeds 8.5 or electrical conductivity values goes above 4 $\mathrm{dS} / \mathrm{m}$, the crop yield goes down (Hussain et al., 2010). Addition of salts to water takes down its osmotic potential, ensuing reduced water availability to root cells. Plants are therefore, exposed to secondary osmotic stress that adversely affect overall physiological activities including growth and development, decrease in photosynthesis, respiration, and protein synthesis and disturbs nucleic acid metabolism. Saline soils expose plants to 2-types of stresses: osmotic stress created by low water potential and accessibility and ionic stress allied to the accumulation of toxic ions (Munns, 2002). Plants cope these harsh environments by salt exclusion and sequestration, tissue tolerance to collected ions and restriction of $\mathrm{K}^{+}$loss, osmotic adjustment and control of water homeostasis, modifications in growth and enlargement and biochemical responses (Shabala and Cuin 2007; Munns and Tester, 2008; Sanchez et al., 2008). Salt tolerance is a quantitative trait determined by multiple genetic interfaces involving changes in the activity of thousands of genes (Monforte et al., 1997; Foolad, 2004; Sanchez et al., 2010). Unfortunately, existing metabolomics methods can only measure a specific portion of metabolomics component (Bino et al., 2004), due to which, it is difficult to identify the concentrations of the accumulated micro-molecules for the osmotic adjustment under salinity stress (Delauney et al., 2002; Foyer and Noctor, 2005; Kishore et al., 2005). In addition, $\mathrm{NaCl}$ stress also provokes a reduction in several organic acids which may recompense for an ionic imbalance (Badri et al., 2008). The changes in metabolomics accumulation or in reduction due to slat stress, may vary from species to species which depends on their genetic makeup. These, variation among various species, recommend a mechanisms that would be species specific, in order to improve tolerance in plants to a number of environmental stresses (Cuin and Shabala, 2007; Szabados and Savouré, 2010).

It has been proposed that modification in metabolomics content to salt stress in some plants, is due to their preadoptability to salinity stress (Sanchez et al., 2008). This hypothesis suggests that extremophile plants had increased level of salt stress-induced metabolites, while a decrease level for those metabolites affected negatively by salt stress. Sanchez et al. (2011) found slight indication of preformed metabolic salt acclimation responses in L. creticus. Both of the supervised and non-supervised analyses of metabolite profiles confirmed that salt-elicited changes in metabolism were universally similar in $L$. creticus and the two glycophytes. Supervised analysis of the metabolite data has shown that the overall pattern of metabolite pools under control conditions did not replicate relative salt tolerance.

Metabolomics limitations of photosynthesis due to amplified $\mathrm{Na}^{+}$and $\mathrm{Cl}^{-}$occur in the leaf tissue $(270 \mathrm{mM})$ under salt stress (Chaves et al., 2009). It has previously been found, that quick changes in gene expression following experimental stress imposition, proposes very quick changes in metabolism. Plant system responses to salt stress are finetuned to the increasing stress by linear, plateau- and threshold-like dose-dependent molecular and metabolic changes (Sanchez et al., 2008). Similar responses were also detected during acclimation to both cold and drought in Arabidopsis thaliana (Wilin et al., 2007; Usadel et al., 2008; Tähtiharju, and Palva, 2001).

Genes imparting to salinity tolerance in crop plants have been widely characterized, especially, those are involved in transcription, transduction, transportation of ion and metabolic (Verma et al., 2007; Singh et al., 2007; Kumari et al., 2009). Few studies have revealed the metabolic influence of salinity on crop plants such as grape vine, rice, tomato, and Arabidopsis (Gong et al., 2005). Metabolic changes may be specific or mutual to all abiotic stress tolerance. For example, levels of sugar alcohols, sugars, and amino acids usually amplify with response to diverse stresses. Proline is mostly accumulated on drought, salinity and cold stress but declines during heat stress (Usadel et al., 2008; Urano et al., 2009; Lugan et al., 2010). In most of the studies, amount of TCA-cycle intermediates and organic acids become deteriorated in glycophytes after salinity stress (Gong et al., 2005), but improved upon drought or temperature stress (Kaplan et al., 2004; Usadel et al., 2008; Urano et al., 2009). Usually, sugars are essential compatible solutes collected in cells during stress responses. Fumagalli et al. (2009) studied the metabolite profile of two different cultivars of rice under salinity $(150 \mathrm{mM})$ and showed enhanced sugar contents during salinity stress in both of the cultivars. Their results also exhibited that salt stress reformed the accumulation of various metabolites in rice, which have vital role in salt tolerance. They also recommended that NMR coupled with principal component analysis (PCA) is impressive tool to characterize rice varieties under salinity or any other stress condition.

Increased salinity modulates the levels of secondary metabolites, which are physiologically significant mainly in stress tolerance. Some of these metabolites have light absorptive properties, whereas others encourage defensive action against herbivores and pathogens (Harborne and Williams, 2000; Taiz and Zeiger, 2002). Most secondary metabolites are synthesized from the intermediates of primary carbon metabolism via phenyl-propanoid, shikimate, mevalonate or MEP pathways (Buchanan et al., 2000). Amongst those, chlorophylls, carotenoids and phenolics are generally studied metabolites in plant kingdom. Improved synthesis of determined secondary metabolites under stressful conditions is supposed to guard the cellular structures from oxidative damage (Buchanan et al., 2000).

Stress-induced variations in primary metabolism lead to diverse levels and classes of secondary metabolites including photosynthetic pigments, flavonoids, phenolics, alkaloids, etc. (Close and McArthor, 2002; Gould et al., 2000; Taiz and Zeiger, 2002). Inflections in the levels of CAR, PHE and flavonoids are of more importance in the inhibition of stress induced oxidative damage or preservation of osmotic balance (Chalker-Scott, 1999; Gould et al., 2000; Sgherri et al., 2004). Negligible decrease in the content of photosynthetic pigments is vital, as it has a direct connection with salinity tolerance (Ahmad et al., 2005). The role of phenolics has been recently reviewed more applicable in oxidative stress tolerance than defence from herbivoures (Close and McArthor, 2002; Sgherri et al., 2004). They showed accumulation under water and salt stresses as well (Dixon and Paiva, 1995; Ali and Abbas, 2003). Flavonoids are acknowledged to guard the sensitive tissues against the harmful effects of UV-radiation (Singh et al., 2004), but their roles have also been envisioned in salinity, as they are ion chelators (Taiz and Zeiger, 2002; Winkel-Shirley, 2002). 

Non-targeted and targeted analysis for the detection of
secondary metabolites

Non-targeted, analytical methods at the gene, transcript, protein and metabolite levels are the methods-of-choice for examining the physiology of the GM plants as widely as possible; thus, enhancing the chances of sensing unintended effects. The application of metabolomics methodology has been revealed to be valuable for the examination of compositional resemblance in GM potatoes. These results are mainly stimulating since they also give deep insights into the degree of distinction within conventional cultivars (Rischer and Oksman-Caldentey, 2006). Non-targeted metabolomics approach is a time-consuming step, and thus cannot be applied to large numbers of biological samples. The variance among non-targeted metabolomics and widely targeted metabolomics is parallel to the change between a whole genome array and an expressed sequence tag-based custom array in transcriptomics (DellaPenna and Last 2008, Lu et al., 2008a; Lu et al., 2008b). A significant problem of untargeted profiling is that it is semi-quantitative and provides relative concentration databased on the same 'surrogate' internal standard. These semi-quantitative data considered to be more authorised via targeted quantitative assays. Targeted profiling is used when it is essential to regulate the exact concentration of a restricted number of identified metabolites and delivers a very low limit of detection. Targeted analysis has been extensively carried out to trail the dynamics of a limited number of metabolites known to be elaborate in a specific stress. It can also be used for relative metabolite profiling of a huge number of identified metabolites. For example, highly similar targeted assays based on selected reaction monitoring (SRM) can be used for very sensitive immediate analysis of over 100 metabolites in a single chromatographic run (Bajad and Shulaev, 2007).

\section{Recent techniques used in plant metabolomics profiling}

Nuclear magnetic resonance (NMR) is a commonly used method to study the assembly of chemical compounds. This NMR-based technique is non-destructive and can be beneficial to molecules in solution and solid state (Berendt et al., 2006). However, the most frequently used is hydrogen-1 NMR, because it is extremely rich and the most amenable isotope at natural abundance. Alternatively, often-used isotope carbon-13 can be used due to its low \%age in natural carbon, which is preferably suited for labelling of compounds in metabolic studies (Jackman and Sternhell, 2013). Recently, NMR based metabolomics studies have been effectively used in plant biotechnology research (Kim et al., 2007; Palama et al., 2010).

Mass spectrometry (MS) is another widely used technique for determination of plant metabolomics. In mass spectrometry the recognition and quantification of compounds is done in more precise way, in which the information about the nature of studied molecules can be obtained by ionizing in positive and negative ion mode (Blaum, 2006). Numerous diverse mass analysers can be used in mass spectrometry including; time-of-flight (TOF) analyzers, quadrupole mass analyzers and ion trap analysers (Feihn et al., 2000).

Liquid chromatography-mass spectrometry is the most advanced and recently used technique in plant metabolomics. It is the combination of different analytical techniques that leads to the separation and quantification of metabolomics in the test samples. The technique is based on a mobile and stationery phase. Since the chemical and physical connections with the solvent and stationary phase are exact for dissimilar chemical classes a huge variety of separation methods exists (Uslu and Uzkan, 2002). Most frequently used method is reversed phase chromatography (RP-HPLC). These methods are used most commonly for the detection of secondary metabolites (Katajamaa and Orešič, 2005).

\section{Next generation sequencing (NGS) a powerful tool to find novel metabolites}

In the recent decade, the next generation sequencing technologies (NGS) have provided opportunities to revolutionize discovery of new metabolites in plants, including biosynthesis pattern of genes, their regulation and pathways, network, etc. through genome-enabled technologies. This has been called the hallmark of $21 \mathrm{st}$ century biology (Kim and Buell, 2015). The approach uses a simple hypothesis of classical forward genetics, by which the novel genes (DNA Sequencing) and their expression (RNASeq) are initially recognized through NGS technologies then the new proteins and metabolites are matched via routine metabolomics techniques and proteogenomics (or metabologenomics). Many novel metabolites affecting plant nutrients, tastes, tolerance to biotics and abiotic stresses, etc. have been found through NGS technologies. Briefly, the DNA of plants producing metabolites of interests is extracted and submitted to one of the NGS core facilities. Currently, up to $80 \%$ of DNA sequencing is carried out by Illumina ${ }^{\circledR}$ technology (read length 120-300 kb). However, some newer technologies such as PacBio® with longer sequencing reads (up to $15 \mathrm{~kb}$ ) have emerged to facilitate the DNA sequencing process with more sensitivity, specificity and reliability (less error rate). The DNA sequencing data undergoes quality checks and then is passed into the De novo assembly and gene annotation process. Many discoveries such as SNP/Indel detection, structural variation, phylogenetic analysis, transcriptome analysis, network analysis, physical cluster identification can be done using freely available web-based and Linux-based bioinformatics tools such as Galaxy platform (https://usegalaxy.org/).

There are too many examples that application of NGS has facilitated discovery of novel secondary metabolites in plants. Kellner et al. (2015) identified a monoterpene indole alkaloid vinblastine in Madagascar periwinkle (Catharanthus roseus). Myburg et al. (2014) discovered a terpene 1,8-cineole in E. grandis. Denoeud et al. (2014) reported the alkaloid caffeine in Coffea canephora. Winzer et al. (2012) explored the phthalide isoquinoline alkaloid noscapine in Poppy (Papaver somniferum) and Quadrana et al. (2014) reported vitamin E metabolites in Tomato. Therefore, the NGS technologies have been an amazing tool to revolutionize the science of metabolomics and to understand the plant metabolism.

\section{Gene editing using CRISPR/Cas9 to design and produce novel metabolites in plants}

The clustered regularly interspersed short palindromic repeats (CRISPR)/Cas9 technology has recently been developed as an efficient nuclease-based method for targeted genome engineering. In this system, only 20-nucleotide target sequences (or even one nucleotide) form the target gene with a desirable sequence of gene needs to be altered (Fig 3). Shan et al. (2014) suggested the (CRISPR)/Cas9 as an appealing system due to its simplicity. They described a stepwise protocol for the selection of target sites, design, construction, 


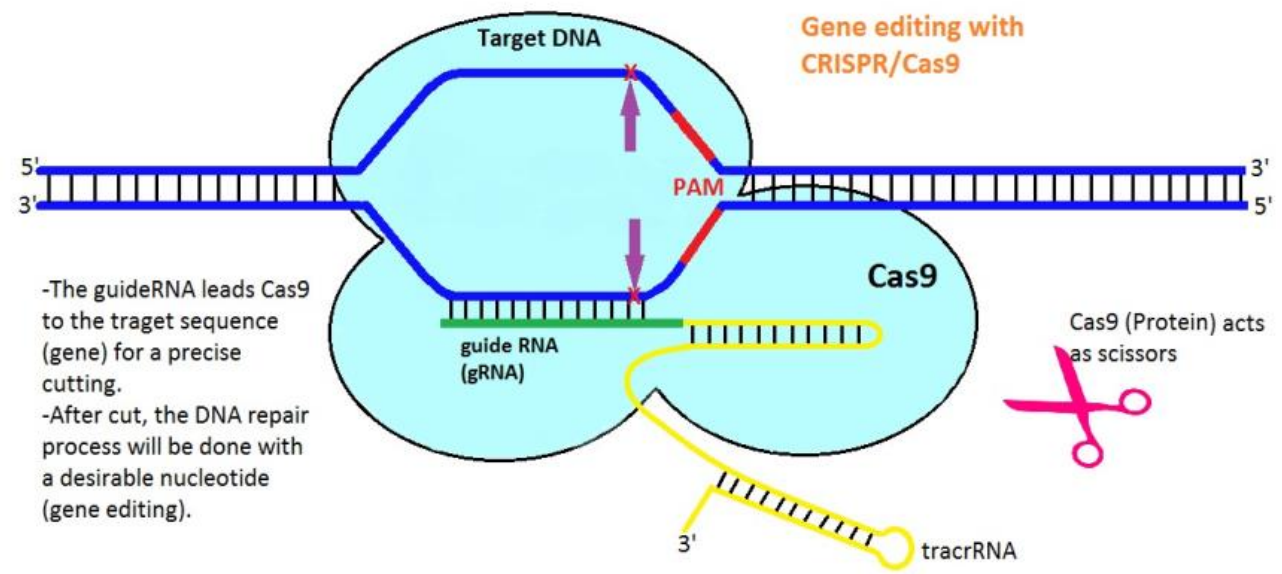

Fig 3. Schematic illustration of genome editing with CRISPR/Cas9 system. The system has consisted of different molecules fused as complex. The Cas9 protein (light blue) is a nuclease that acts as scissors to cut the DNA site (purple arrows). The system cleaves 20 nt of DNA double strand of targeted gene. The gene will be targeted (harbored) based on design of gRNA. The gRNA is single strand (green and yellow) and leads the Cas9 to the desired cutting place. The editing will be occurred during repair (HDR) process, where a designed oligo template repairs the double strand break created by Cas9 (adapted from Redman et al., 2016).

verification and use of single guide RNA (sgRNAs) for sequence-specific mutagenesis in target genes of rice and wheat. Since its emergence in 2013, this new technology has been suggested by many researches to be cheap, safe and efficient for human cancer therapy such as lung and blood cancer (Sachdeva et al., 2015; Sánchez-Rivera and Jacks, 2015). Therefore, this system can be considered extremely safe in crop gene editing for better tolerance to biotic and abiotic stresses, nutritional quality (Kharabian-Masouleh and Henry, 2015) and creating new metabolites.

Genome wide association studies (GWAS) acts as a bridge between NGS and phenotypic data to recognize metabolite targets for CRISPR/Cas9 editing

Through the NGS methods millions of SNPs can be discovered in a genome, in which many of them belong to secondary metabolites. Availability of phenotypic data and SNP mapping in a genome enable us to discover association at a genome wide scale. Cheng et al. (2014) sequenced 529 rice accessions and generated 6.4 million SNPs, responsible for 840 metabolites, which finally let to identify 36 candidate metabolite modulating genes with potential physiological and nutritional importance. Glucosinolates are amino acids (derived from secondary metabolites) with significant roles in plant defense against insects and pathogens. Cheng et al. (2010) found more than 200,000 SNPs in 96 Arabidopsis accessions to assess the natural diversity of 43 glucosinolate phenotypes. In total, they found 172 genes, containing SNPs associated with variation in glucosinolate profiles. Out of all 172, 3 genes [Alkenyl Hydroxalkyl Producing2 (AOP2) and $A O P 3$ and Methylthioalkylmalate Synthase1 (MAMI)] controlled glucosinolate-related QTL. After recognition of genes containing SNPs with direct effects on metabolites, they can be edited with CRISPR/Cas9 technology to produce novel metabolic compounds, with more or even less abundances.

\section{Conclusion}

In response to abiotic stress, plants arrange a collection of responses including stress avoidance, resistance or defence, dependent on stress type. These defence and resistance mechanisms are related with metabolomics modifications. Metabolomics could pay expressively to the study the stress biology in plants and other organisms by recognising dissimilar compounds, such as by-products of stress metabolism, stress signal transduction molecules or molecules that are part of the acclimation response of plants. Secondary metabolites show important physiological role in salinity tolerance, particularly beside oxidative damage. Such roles of these metabolites are restricted to the compartment, where they accumulate. To further understand the intricacy of plant response to drought and salt, with the effects on photosynthesis, we have to strengthen multi-level genomics and physiological studies, casing diverse intensity and timing of burden of the stresses in genotypes with diverse sensitivity to stress. It is previously deceptive that an important number of genes linked to photosynthetic metabolism is quickly down or upregulated in response to drought and salt stress.

\section{References}

Ahmad S, Wahid A, Rasul E, Wahid A (2005) Comparative morphological and physiological responses of green gram genotypes to salinity applied at different growth stages. Bot Bull Acad Sin. 46:135-42.

Ali RM, Abbas HM (2003) Response of salt stressed barley seedlings to phenylurea. Plant Soil Envir. 49(4):158-162.

Alvarez EL, Marsh SG, Schroeder DP, Schachtman (2008) Metabolomic and proteomic changes in the xylem sap of maize under drought. Plant Cell Environ. 31:325-340.

Arbona V, Manzi M, Ollas CD, Gómez-Cadenas A (2013) Metabolomics as a tool to investigate abiotic stress tolerance in plants. Int J Molec Sci. 14(3):4885-4911.

Badri DV, Loyola-Vargas VM, Broeckling CD, De-la-Peña C, Jasinski M, Santelia D, Martinoia E, Sumner LW, Banta LM, Stermitz F, Vivanco JM (2008) Altered profile of secondary metabolites in the root exudates of Arabidopsis ATP-binding cassette transporter mutants. Plant Physio 1:146 (2):762-71.

Bajad S, Shulaev V (2007) Highly-parallel metabolomics approaches using LC-MS2 for pharmaceutical and environmental analysis. Trends Analyt Chem. 26: 625-636.

Bartels, Dorothea, Ramanjulu S (2005) Drought and salt tolerance in plants. Crit Rev Plant Sci. 24:1: 23-58.

Berendt, Robert T, Diana M, Sperger, Eric J, Munson, Paul K, Isbester (2006) "Solid-state NMR spectroscopy in pharmaceutical research and analysis. TrAC Trends Ana Chem. 25(10): 977-984. 
Bino RJ, Hall RD, Fiehn O, Kopka J, Saito K, Draper J, Nikolau BJ, Mendes P, Roessner-Tunali U, Beale MH (2004) Potential of metabolomics as a functional genomics tool. Trends Plant Sci.9:418-425.

Blaum K (2006) High-accuracy mass spectrometry with stored ions. Physic Rep. 425(1): 1-78.

Boyer JS, Westgate ME (2004) Grain yields with limited water. J Exp Bot. 55:2385-2394

Buchanan BB, Gruissem W, Jones R (2000) Biochemistry and molecular biology of plants. Maryland Amer Soci Plant Physio. ISBN: 978-0-470-71421-8

Bundy JG, Keun H, Sidhu JK, Spurgeon DJ, Svendsen C, Kille P, Morgan AJ (2007) Metabolic profile biomarkers of metal contamination in a sentinel terrestrial species are applicable across multiple sites. Environ Sci Technol. 41: $4458-4464$.

Cairns JE, Hellin J, Sonder K, Araus JL, MacRobert JF, Thierfelder C, Prasanna BM (2013) Adapting maize production to climate change in sub-Saharan Africa. Food Security. 5(3): 345-360.

Chalker-Scott L (1999) Environmental significance of anthocyanins in plant stress responses. Photochem. Photobiol.70:1-9.

Chan EKF, Rowe HC, Kliebenstein DJ (2010) Understanding the evolution of defense metabolites in Arabidopsis thaliana using genome-wide association mapping. Genetics. 185: 991-1007

Charlton AJ, Donarski JA, Harrison M, Jones SA, Godward J, Oehlschlager S, Arques JL, Ambrose M, Chinoy C, Mullineaux PM, Domoney C (2008) Responses of the pea (Pisum sativum L.) leaf metabolome to drought stress assessed by nuclear magnetic resonance spectroscopy. Metabolomics. 4(4):312.

Chaves MM, Flexas J, Pinheiro C (2009) Photosynthesis under drought and salt stress: regulation mechanisms from whole plant to cell. Ann Bot. 103 (4):551-560.

Chaves MM, Maroco JP, Periera S (2002) Understanding plant responses to drought from genes to the whole plant. Funct Plant Biol.30:239-64.

Chawla K, Barah P, Kuiper M, Bones AM (2011) Systems biology: a promising tool to study abiotic stress responses. Omics and Plant Abiotic Stress Tolerance. 163-172.

Chen W, Gao Y, Xie W, Gong L, Lu K, Wang W, Li Y, Liu X, Zhang H, Dong H, Zhang W, Zhang L, Yu S, Wang G, Lian X, Luo J (2014) Genome-wide association analyses provide genetic and biochemical insights into natural variation in rice metabolism. Nat Genet. 46: 714-721.

Close DC, McArthor C (2002) Rethinking the role of many plant phenolics-protection against photodamage not herbivores. 99:166-72.

Colinet H, Larvor V, Laparie M, Renault D (2012) Exploring the plastic response to cold acclimation through metabolomics. Funct Ecol. 26: 711-722.

Collins NF. Tardieu, Tuberosa R (2008) Quantitative trait loci and crop performance under abiotic stress: where do we stand. Plant Physiol. 147:469-486.

Cuin TA, Shabala S (2007) Amino acids regulate salinityinduced potassium efflux in barley root epidermis. Planta. 25: 753-761

Davies WJ (2006) Responses of plant growth and functioning to changes in water supply in a changing climate. Plant Growth Climate Change. Oxford, UK. 96-117.

Delauney A, Pflieger D, Barrault MB, Vinh J, Toledano MB (2002) A thiol peroxidase is an $\mathrm{H} 2 \mathrm{O} 2$ receptor and redoxtransducer in gene activation. Cell. 111:1-11

DellaPenna D, Last RL (2008) Genome-enabled approaches shed new light on plant metabolism. Science. 320:479-481.
Dixon RA, Paiva NL (1995) Stress induced phenylpropanoid metabolism. Plant Cell. 7:1085-97.

Denoeud F, Carretero-Paulet L, Dereeper A, Droc G, Guyot R, Pietrella M, Zheng C, Alberti A, Anthony F, Aprea G, et al. (2014) The coffee genome provides insight into the convergent evolution of caffeine biosynthesis. Science. 345: 1181-1184

Fiehn O (2002) Metabolomics-the link between genotypes and phenotypes. Plant Mol. Bio. 48: 155-171.

Fiehn O, Kopka J, Trethewey RN, Willmitzer L (2000) Identification of uncommon plant metabolites based on calculation of elemental compositions using gas chromatography and quadrupole mass spectrometry. Anal Chem. 72(15):3573-3580.

Foolad MR (2004) Recent advances in genetics of salt tolerance in tomato. Plant Cell Tiss Oorg Cult. 76:101-119.

Foyer CH, Noctor G (2005) Redox homeostasis and antioxidant signaling: a metabolic interface between stress perception and physiological responses. The Plant Cell.17 (7):1866-1875

Fumagalli E, Baldoni E, Abbruscato P, Piffanelli P, Genga A, Lamanna R, Consonni R (2009) NMR techniques coupled with multivariate statistical analysis: tools to analyse Oryza sativa metabolic content under stress conditions. J Agron. Crop Sci.195 (2):77-88.

Geigenberger P, Stitt M, Fernie AR (2004) Metabolic control analysis and regulation of the conversion. Plant Cell Environ. 27: 655-673.

Gong Q, Li P, Ma S, Indu Rupassara S, Bohnert HJ (2005) Salinity stress adaptation competence in the extremophile Thellungiella halophila in comparison with its relative Arabidopsis thaliana. Plant J. 44(5):826-39.

Gould KS, Markham KR, Smith RH, Goris JJ (2000) Functional role of anthocyanins in the leaves of Quintinia serrata A. Cunn J Exp Bot. 51:1107-15.

Guy C, Kaplan F, Kopka J, Selbig J, Hincha DK (2008) Metabolomics of temperature stress. Physiol Plant. 132:220-235.

Halford NG and Hey SJ (2009) Snf1-related protein kinases (SnRKs) act within an intricate network that links metabolic and stress signalling in plants. Biochem J. 419(2):247-59.

Hansen J, Fung I, Lacis A, Rind D, Lebedeff S, Ruedy R, Ru ssell G, Stone P (1988) Global climate changes as forecast by Goddard Institute for Space Studies three-dimensional model. J Geophys Res. 93:9341-9364.

Harborne JB, Williams CA (2000) Advances in flavonoid research since 1992. Phytochem. 55:481-504.

Hollywood K, Daniel RB, Goodacre R (2006) Metabolomics: Current technologies and future trends. Proteom. 6: 47164723.

Hussain N, Sarwar G, Schmeisky H, Al-Rawahy S, Ahmad M (2010) Salinity and drought management in legume crops. In Climate Change and Management of Cool Season Grain Legume Crops (pp. 171-191). Springer Netherlands.

Ideker T, Thorsson V, Ranish JA, Christmas R, Buhler J, Eng JK, Bumgarner R, Goodlett DR, Aebersold R, Hood L (2011) Integrated genomic and proteomic analyses of a systematically perturbed metabolic network. Science. 4:292 (5518):929-34

Jackman LM, Sternhell S (2013) Application of Nuclear Magnetic Resonance Spectroscopy in Organic Chemistry: Inter. Series in Organic Chem. Elsevier.

Janská A, Aprile A, Zámečník J, Cattivelli L, Ovesná J (2011) Transcriptional responses of winter barley to cold indicate nucleosome remodelling as a specific feature of crown tissues. Funct Integ Genom. 1:11(2):307-25. 
Kaplan F, Guy CL (2004) Beta-Amylase induction and the protective role of maltose during temperature shock. Plant Physio.135:1674-1684.

Katajamaa M, Orešič M (2005) Processing methods for differential analysis of LC/MS profile data. BMC Bioinformatics. 6(1):179.

Kaur S, Gupta AK, Kaur N (2002) Seed priming increases crop yield possibly by modulating enzymes of sucrose metabolism in chickpea. J Agron Crop Sci. 191, 81-87.

Kellner F, Kim J, Clavijo BJ, Hamilton JP, Childs KL, Vaillancourt B, Cepela J, Habermann M, Steuernagel B, Clissold L, et al. (2015) Genome-guided investigation of plant natural product biosynthesis. Plant J. 82: 680-692.

Kerchev PI, Fenton B, Foyer CH, Hancock RD (2012) Plant responses to insect herbivory: Interactions between photosynthesis, reactive oxygen species and hormonal signalling pathways. Plant Cell Environ. 35:441-453.

Kharabian-Masouleh A, Henry RJ (2015) Genome editing can boost yield and quality in rice. TropAg2015. 16-18 November, Brisbane, Australia.

Kim JK, Bamba T, Harada K, Fukusaki E, Kobayashi A (2007).Time-course metabolic profiling in Arabidopsis thalianacell cultures after salt stress treatment. J Exp Bot. 58:415-424.

Kim SW, Ban SH, Jeong SC (2007) Genetic discrimination between Catharanthus roseus cultivars by metabolic fingerprinting using $1 \mathrm{~h}$ NMR spectra of aromatic compounds. Biotechnol. Bioprocess Eng. 12:646-652.

Kim J, Buell CR (2015) A revolution in plant metabolism: Genome-enabled pathway discovery. Plant Physiol. 169 (3) 1532-1539.

Kishore PB, Kavi, Sangam S, Amrutha RN, Laxmi PS, Naidu KR, Rao KRSS, Rao S, Reddy KJ, Theriappan P, Sreenivasulu N (2005) Regulation of proline biosynthesis, degradation, uptake and transport in higher plants: its implications in plant growth and abiotic stress tolerance. Curr Sci. 88(3): 424-438.

Koch K (2004) Sucrose metabolism: regulatory mechanisms and pivotal roles in sugar sensing and plant development. Curr. Opin. Plant Biol. 7:235-246.

Korn M, Gärtne T, Erban A, Kopka J, Selbig J, Hincha DK (2010) Predicting Arabidopsis freezing tolerance and heterosis in freezing tolerance from metabolite composition. Mol Plant. 3:224-235.

Krasensky J, Jonak C (2012) Drought, salt and temperature stress-induced metabolic rearrangements and regulatory networks. J Exp Bot. 63: 1593-1608.

Kumari S, nee Sabharwal VP, Kushwaha HR, Sopory SK, Singla-Pareek SL, Pareek A (2009) Transcriptome map for seedling stage specific salinity stress response indicates a specific set of genes as candidate for saline tolerance in Oryza sativa L. Funct Integ Genom. 9(1):109-123.

Kusano M, Redestig H, Hirai T, Oikawa A, Matsuda F, Fukushima A, Arita M, Watanabe S, Yano M, HiwasaTanase K, Ezura H, Saito K (2011) Covering chemical diversity of genetically modified tomatoes using metabolomics for objective substantial equivalence assessment. PLoS ONE. 6:e16989.

Kushiro T, Okamoto M, Nakabayashi K, Yamagishi K, Kitamura S, Asami T, Hirai N, Koshiba T, Kamiya Y, Nambara E (2004) The Arabidopsis cytochrome P450 CYP707A encodes ABA 80 -hydroxylases: key enzymes in ABA catabolism. EMBO J. 23:1647-1656.

Lee YP, Babakov A, de Boer B, Zuther E, Hincha DK (2012) Comparison of freezing tolerance, compatible solutes and polyamines in geographically diverse collections of
Thellungiella sp. and Arabidopsis thaliana accessions. BMC Plant Biol. 12:131.

Lewis DFV, Gorrod JW (2002) Molecular orbital calculations and nicotine metabolism: a rationale for experimentally observed metabolite ratios. Drug Metabo Drug Interact. 19(1):29-40.

Lijima Y (2014) Recent advances in the application of metabolomics to studies of biogenic volatile organic compounds (BVOC) produced by plant. Metabolites. 4(3):699-721.

Lu W, Bennett BD, Rabinowitz JD (2008a) Analytical strategies for LC-MS-based targeted metabolomics. J Chromatogr. B.871:236-242.

Lu Y, Savage LJ, Ajjawi I, Imre KM, Yoder DW, Benning C (2008b) New connections across pathways and cellular processes: industrialized mutant screening reveals novel associations between diverse phenotypes in Arabidopsis. Plant Physiol.146:1482-1500.

Lugan R, Niogret MF, Leport L, Guegan JP, Larher FR, Savoure A, Kopka J, Bouchereau A (2010) Metabolome and water homeostasis analysis of Thellungiella salsuginea suggests that dehydration tolerance is a key response to osmotic stress in this halophyte. Plant J. 64:215-229.

Luo J (2015) Metabolite-based genome-wide association studies in plants. Curr Opin Plant Biol. 24: 31-38.

Mitchell-Olds T, Pedersen D (1998) The molecular basis of quantitative genetic variation in central and secondary metabolism in Arabidopsis. Gene. 149:739-747.

Mittler R, Vanderauwera S, Gollery M, Van Breusegem, F (2004) Reactive oxygen gene network of plants. Trend Plant Sci. 9(10), 490-498.

Moongngarm A, Saetung N (2010) Comparison of chemical compositions and bioactive compounds of germinated rough rice and brown rice. Food Chem. 1:122(3):782-8.

Monforte AJ, Asins MJ, Carbonell EA (1997) Salt tolerance in Lycopersicon species. VI. Genotype-by-salinity interaction in quantitative trait loci detection: constitutive and response QTLs. Theor Appl Genet. 95:706-713.

Morison JIL, Neil RB, Philip MM, William J (2008) Improving water use in crop production. Philosophical Transactions of the Royal Society of London B: Biol. Sci. 363, no. 1491: 639-658.

Munns R (2002) Comparative physiology of salt and water stress. Plant Cell Environ. 25:239-250.

Munns R, Tester M (2008) Mechanisms of salinity tolerance. Ann Rev Pl Bio. 59:651-681.

Myburg AA, Grattapaglia D, Tuskan GA, Hellsten U, Hayes RD, Grimwood J, Jenkins J, Lindquist E, Tice H, Bauer D, et al. (2014) The genome of Eucalyptus grandis. Nature 510: 356-362.

Nilsen ET, Orcutt DM (1996) Stable isotopes and plant stress physiology. In: Nilsen ET, Orcutt DM, eds. Physiology of plants under stress. Abiotic factors. New York: John Wiley \& Sons, Inc. 199-230.

Obata T, Fernie AR (2012) The use of metabolomics to dissect plant responses to abiotic stresses. Cell Mol Life Sci. 69(19):3225-3243.

Oksman-Caldentey KM, Saito K (2005) Integrating genomics and metabolomics for engineering plant metabolic pathways. Curr Opin Biotech.16:174-179.

Ortiz, Rodomiro, Kenneth D, Sayre, Bram Govaerts, Raj Gupta, Subbarao GV, Tomohiro Ban, David Hodson, John M, Dixon J, Iván OM, Reynolds M (2008) Climate change: Can wheat beat the heat?. Agri Eco Envir. 126(1): 46-58.

Palama TL, Menard P, Fock I, Choi YH, Bourdon E, Goviden-Soulange J, Bahut M, Payet B, Verpoorte R, Kodja H (2010) Shoot differentiation from protocorm 
callus cultures of Vanilla planifolia (Orchidaceae): proteomic and metabolic responses at early stage. BMC Plant Biol. 10:82.

Patti GJ, Yanes O, Siuzdak G (2012) Innovation: Metabolomics: the apogee of the omics trilogy. Nat Rev Mol Cell Biol. 13: 263-269.

Pelleschi S, Leonardi A, Rocher JP, Cornic G, De Vienne D, Thevenot C, Prioul JL (2006) Analysis of the relationships between growth, photosynthesis and carbohydrate metabolism using quantitative trait loci (QTLs) in young maize plants subjected to water deprivation. Mole. Breeding. 1:17(1):21-39.

Perry AL, Low PJ, Ellis JR, Reynolds JD (2005) Climate change and distribution shifts in marine fishes. Science. 308(5730), 1912-1915.

Pinhero RG, Rao MV, Palyath G, Murr DP, Fletcher RA (2001) Changes in the activities of antioxidant enzymes and their relationship to genetic and paclobutrazol-induced chilling tolerance of maize seedlings. Plant Physiol. 114:695-704

Pittock B (2003) Climate change and Australia's natural resources. A review. In: Proceedings of the Conference on Climate Impacts on Australia's Natural Resources: Current and Future Challenges, Queensland, Australia. Canberra: Standing Committee on Natural Resource Management. Managing Climate Variability Program. 51-2.

Quadrana L, Almeida J, Asís R, Duffy T, Dominguez PG, Bermúdez L, Conti G, Corrêa da Silva JV, Peralta IE, Colot $\mathrm{V}$, et al. (2014) Natural occurring epialleles determine vitamin $\mathrm{E}$ accumulation in tomato fruits. Nat Commun. 5: 3027.

Redman Melody, King Andrew, Watson Caroline, King David (2016) What is CRISPR/Cas9? Arch Dis Child Educ Pract Ed. 101:213-215. doi:10.1136/archdischild-2016310459

Richardson DHS (1993) The physiology of drying and rewetting in lichens. 275-296.

Rischer H, Oksman-Caldentey KM (2006) Unintended effects in genetically modified crops: revealed by metabolomics. Tren Biotech. 24(3):102-104.

Rochfort SJ, Trenerry VC, Imsic M, Panozzo J, Jones R (2008) Class targeted metabolomics: ESI ion trap screening methods for glucosinolates based on MSn fragmentation. Phytochem. 69:1671-1679.

Rolland F, Baena-Gonzalez E, Sheen J (2006) Sugar sensing and signalling in plants: conserved and novel mechanisms. Ann Rev P Bio. 57:675-709

Rontein D, Dieuaide-Noubhani M, Dufourc EJ, Raymond P, Rolin D (2002) The metabolic architecture of plant cells. Stability of central metabolism and flexibility of anabolic pathways during the growth cycle of tomato cells. J. Biol. Chem. 277:43948-43960.

Sachdeva M, Sachdeva N, Pal M, Gupta N, Khan IA, Majumdar M and Tiwari A (2015) CRISPR/Cas9: molecular tool for gene therapy to target genome and epigenome in the treatment of lung cancer. Cancer Gene Therapy. 22:509-517; doi:10.1038/cgt.2015.54.

Saito S, Hirai N, Matsumoto C, Ohigashi H, Ohta D, Sakata K, Mizutani M (2004) Arabidopsis CYP707As encode (+)abscisic acid 80 -hydroxylase, a key enzyme in the oxidative catabolism of abscisic acid. Plant Physiol. 134:1439-1449.

Saito K, Matsuda F (2010) Metabolomics for functional genomics, systems biology, and biotechnology. Annu Rev Plant Biol. 61:463-489.

Sanchez DH, Pieckenstain FL, Escaray F, Erban A, Kraemer U, Udvardi MK, Kopka J (2011) Comparative ionomics and metabolomics in extremophile and glycophytic Lotus species under salt stress challenge the metabolic pre-adaptation hypothesis. Plant Cell Environ. 34:605-617.

Sanchez DH, Lippold F, Redestig H, Hannah M, Erban A, Krämer U, Kopka J, Udvardi MK (2008) Integrative functional genomics of salt acclimatization in the model legume Lotus japonicus. Plant J. 53:973-987.

Sánchez-Rivera FJ and Jacks T (2015) Applications of the CRISPR-Cas9 system in cancer biology. Nat Rev Cancer. 15(7): 387-395.doi:10.1038/nrc3950.

Sgherri C, Stevanovic B, Navari-Izzo F (2004) Role of phenolics in the antioxidative status of the resurrection plant Ramonda serbica during dehydration and rehydration. Physiol Plant. 122:478-88.

Shabala S, Cuin TA (2007) Potassium transport and plant salt tolerance. Physio Plant. 133: 651-669.

Shan Q, W Yang, Li J and Gao C (2014) Genome editing in rice and wheat using the CRISPR/Cas system. Nature Protocol. 9(10):2395-2410. doi:10.1038/nprot.2014.157

Shao HB, Chu LY, Jaleel CA, Manivannan P, Panneerselvam R, Shao MA (2009) Understanding water deficit stressinduced changes in the basic metabolism of higher plantsbiotechnologically and sustainably improving agriculture and the ecoenvironment in arid regions of the globe. Crit. Rev. Biotechnol.29: 131-151.

Shulaev V (2006) Metabolomics technology and bioinformatics. Brief Bioinform. 7: 128-139.

Singh JPV, Selvendiran K, Banu SM, Padmavathi R, Sakthisekaran D (2004) Protective role of Apigenin on the status of lipid peroxidation and antioxidant defense against hepatocarcinogenesis in Wistar albino rats. Phytome. 11 (4):309-314.

Singh RK, Gregorio GB, Jain RK (2007) QTL mapping for salinity tolerance in rice. Physiol Mol Biol Plants. 13: 8799.

Suzuki N, Mittler R (2013) Reactive oxygen speciesdependent wound responses in animals and plants. Free Radicals Biology Medicine. 53: 2269-2276.

Szabados L, Savouré A (2010) Proline: a multifunctional amino acid. Trends Plant Sci. 15:89-97.

Tähtiharju S, Palva T (2001) Antisense inhibition of protein phosphatase $2 \mathrm{C}$ accelerates cold acclimation in Arabidopsis thaliana. Plant J. 26 (4):461-470

Taiz L, Zeiger E (2002) Plant physiology, 3rd ed. Massachusetts: Sinauer Associates Inc Publishers.

Tardieu F, Tuberosa R (2010) Dissection and modelling of abiotic stress tolerance in plants. Curr Opin Plant Biol. 13: 206-212.

Tarpley L, Duran AL, Kebrom TH, Sumner LW (2005) Biomarker metabolites capturing the metabolite variance present in a rice plant developmental period. BMC Plant Bio. 31:5(1):8.

Urano K, Maruyama K, Ogata Y (2009) Characterization of the ABA-regulated global responses to dehydration in Arabidopsis by metabolomics. Plant J. 57:1065-1078.

Usadel B, Blasing OE, Gibon Y, Poree F, Hohne M, Gunter M, Trethewey R, KamlageB, Poorter H, Stitt M (2008) Multilevel genomic analysis of the response of transcripts, enzyme activities and metabolites in Arabidopsis rosettes to a progressive decrease of temperature in the non-freezing range. Plant Cell and Enviro. .31:518-547.

Uslu B, Özkan SA (2002) Determination of lamivudine and zidovudine in binary mixtures using first derivative spectrophotometric, first derivative of the ratio-spectra and high-performance liquid chromatography-UV methods. Analytica Chimica Acta. 466(1):175-185. 
Valerio C, Costa A, Marri L, Issakidis-Bourguet E, Pupillo P, Trost P, Sparla F (2011) Thioredoxin-regulated betaamylase (BAM1) triggers diurnal starch degradation in guard cells, and in mesophyll cells under osmotic stress. J Exp Bot. 62:545-555.

Verma D, Singla-Pareek SL, Rajagopal D, Reddy MK, Sopory SK (2007) Functional validation of a novel isoform of $\mathrm{Na}+\mathrm{H}+$ antiporter from Pennisetum glaucum for enhancing salinity tolerance in rice. J Biosci. 32 (3):621628.

Wakasa K, Hasegawa H, Nemoto H, Matsuda F, Miyazawa H, Tozawa Y, Morino K, Komatsu A, Yamada T, Terakawa T, Miyagawa H (2006) High-level tryptophan accumulation in seeds of transgenic rice and its limited effects on agronomic traits and seed metabolite profile. J Exp Bot. 1:57(12):3069-78.

Widodo Patterson JH, Newbigin E, Tester M, Bacic A, Roessner U (2009) Metabolic responses to salt stress of barley (Hordeum vulgare L.) cultivars, Sahara and Clipper, which differ in salinity tolerance. J Exp Bot. 60:40894103.

Wink M (1988) Plant breeding: importance of plant secondary metabolites for protection against pathogens and herbivores. Theor Appl Genet. 1:75(2):225-33.

Winkel-Shirley B (2002) Biosynthesis of flavonoids and effects of stress. Curr Opin Plant Biol. 5:218-23.
Witt S, Galicia L, Lisec J, Cairns J, Tiessen A, Araus JL, Palacios-Rojas N, Fernie AR (2012) Metabolic and phenotypic responses of greenhouse-grown maize hybrids to experimentally controlled drought stress. Mol Plant. 5:401-417.

Winzer T, Gazda V, He Z, Kaminski F, Kern M, Larson TR, Li Y, Meade F, Teodor R, Vaistij FE, et al. (2012) A Papaver somniferum 10-gene cluster for synthesis of the anticancer alkaloid noscapine. Science. 336: 1704-1708.

Yonekura-Sakakibara K, Tohge T, Matsuda F, Nakabayashi R, Takayama H, Niida R, Watanabe-Takahashi A, Inoue E, Saito K (2008) Comprehensive flavonol profiling and transcriptome coexpression analysis leading to decoding gene-metabolite correlations in Arabidopsis. Plant Cell. 20:2160-2176.

Yuwan JS, Galbraith DW, Dai SY, Griffin P, Stewart CN (2008) Plant systems biology comes of age. Trends Plant Sci. 13: 165-171

Zhao J, Davis LC, Verpoorte R (2005) Elicitor signal transduction leading to production of plant secondary metabolites. Biotech Adv. 23(4):283-333. 